\title{
MAPEAMENTO DO DESMATAMENTO EM SÃO FÉLIX DO XINGÚ UTILIZANDO COMPOSIÇÃO COLORIDA MULTITEMPORAL DE IMAGENS FRAÇÕES SOMBRA
}

\section{mapping deforestation in São Félix do Xingú using multi-temporal color composite of shade fraction images}

Fernando Shinji Kawakubo ${ }^{1}$

Rubia Gomes Morato ${ }^{2}$

Ailton Luchiari ${ }^{3}$

$a a_{a} a$

\begin{abstract}
Resumo
O objetivo deste trabalho consiste em mapear o avanço do desmatamento no município de São Félix do Xingu, Sul do Pará (Amazônia Brasileira) usando imagens Landsat TM. A técnica do modelo linear de mistura espectral (MLME) foi empregada para realçar as áreas desmatadas. Três imagens frações representando as proporções de solo exposto, vegetação e sombra foram derivadas do MLME. O mapeamento do desmatamento foi feito utilizando os atributos da imagem-fração sombra que é bem correlacionada com a estrutura do dossel florestal. Após a segmentação, as regiões foram agrupadas por um classificador não-supervisionado por regiões ISOSEG.
\end{abstract}

Palavras-chave: Desmatamento, modelo de mistura, imagem fração-sombra, análise multitemporal.

\begin{abstract}
The aim of this work consists of mapping deforestation in São Félix do Xingú, Southern Pará (Brazilian Amazon) using Landsat TM images. Three fraction images representing proportion of bare soil, vegetation, and shade were estimated from the Liner Spectral Mixture Model (LSMM). We choose in this study the shade fraction to discriminate cleared areas because it is well correlated with forest structure. While undisturbed tropical forests usually have medium proportion of shade, cleared areas have low shade content. After segmentation, the homogeneous regions were grouped using an unsupervised classifier named ISOSEG.
\end{abstract}

Key words: Deforestation, Mixture model, Shade fraction image, Multi-temporal analysis.

\begin{abstract}
Resumen
El objetivo del trabajo es mapear el progreso de la deforestación en el municipio de São Félix do Xingu, Sur de Pará (amazonía brasileña), utilizando imágenes Landsat TM. La técnica del modelo lineal de mezcla espectral (MLME) fue empleada para reducir el volumen de datos y destacar las áreas deforestadas. Tres imágenes-fracción que representan las proporciones de suelo expuesto, vegetación y sombra se derivaron del MLME. El mapeo de la deforestación se ha hecho utilizando los atributos del imagen-fracción sombra que se correlaciona bien con la estructura de la cubierta forestal: mientras que las zonas de bosques intactas tienen un medio coeficiente de sombra (en función de la rugosidad de la cubierta), el barbecho, las áreas de pastizales y suelo desnudo poseen una baja proporción en sus estructuras. Después de la segmentación, las regiones se combinaron con un clasificador no supervisado por regiones denominado como ISOSEG.
\end{abstract}

Palabras clave: Deforestación, Modelo de mezcla espectral, Imágenes-fracción sombra.

(1) Prof. Dr. do Instituto de Ciências da Natureza, Universidade Federal de Alfenas - Rua Gabriel Monteiro da Silva, 700, Centro, CEP: 37.130-000, Alfenas , (MG) - Brasil, Tel: (+ 55 35)32991449 - fskgeo@gmail.com

(2) Prof ${ }^{a}$. Dr ${ }^{\mathrm{a}}$. do Instituto de Ciências da Natureza, Universidade Federal de Alfenas - Rua Gabriel Monteiro da Silva, 700, Centro, CEP: 37.130-000, Alfenas , (MG) - Brasil, Tel: (+ 55 35)32991449 - rubiagm@usp.br

3) Prof. Dr. do Programa de Pós-Graduação em Geografia Física da Universidade de São Paulo - Av. Prof. Lineu Prestes, 338, CEP: 05580999 - São Paulo (SP), Brasil. Tel: (+ 55 11) 30913769 - aluchiar@usp.br

\section{aaCaa}




\section{INTRODUÇÃO}

A extração de informação temática a partir do processamento e interpretação de imagens de sensoriamento remoto é uma das áreas de aplicações mais importantes da Geografia. A última década tem sido marcada pelos lançamentos de vários satélites de sensoriamento remoto, que tem proporcionado aos usuários desta tecnologia uma ampla gama de possibilidades de aplicações que se estendem da escala de detalhe à análise regional.

Os estudos relacionados ao mapeamento do desmatamento na Amazônia Brasileira tem se beneficiado com os avanços tecnológicos do sensoriamento remoto. O principal projeto de estimativa de desflorestamento da Amazônia Brasileira é chamado Programa de Monitoramento do Desmatamento da Amazônia Legal (PRODES-Digital) que utiliza imagens Landsat-TM e CBERS-CCD (30 e 20 metros no terreno, respectivamente) para detectar o desmatamento de corte raso em áreas superiores a 6,25 hectares (INPE, 2008). O PRODES-Digital é encabeçado pelo Instituto Nacional de Pesquisas Espaciais (INPE) sendo os seus dados disponibilizados no endereço eletrônico: http:// www.obt.inpe.br/prodes.

Além das imagens com resolução espacial de 20 a 30 metros no terreno, imagens de resolução mais fina, como as do satélite Ikonos-2 - com 1 metro no modo pancromático e 4 metros no modo multiespectral - têm sido utilizadas com sucesso para mapear com detalhe o processo de degradação florestal causado pelo corte seletivo de madeira (SOUZA JR.; ROBERT, 2005).

$\mathrm{Na}$ escala regional, imagens com resolução espacial que variam de 250 a 1000 metros (por exemplo, as imagens geradas pelo sistema MODIS, Spot Vegetação e AVHRR-NOAA) têm sido utilizadas para mapear o uso da terra e cobertura vegetal (RODRIGEZ YI et al. 2000; CARREIRAS et al. 2002; MORTON et al. 2006), a extensão das florestas secundárias na Amazônia Legal (LUCAS et al. 2000; LUCAS et al. 2002) e para o monitoramento do desmatamento (ANDERSON et al. 2005). Por se tratar de sistemas que abrangem grandes áreas e com alta frequência temporal, estes sistemas ampliam o potencial de adquirir informações no terreno em regiões que são frequentemente cobertas por nuvens. O sistema desenvolvido pelo INPE para o apoio à fiscalização e controle do desmatamento da Amazônia (DETER) utiliza imagens do sensor Moderate Resolutin Imaging Spectroradiometer (MODIS) para gerar mensalmente mapas de alertas com áreas maiores que 25 hectares (http://www.obt.inpe.br/deter/).

Uma das principais técnicas empregadas para reduzir o volume de dados e ao mesmo tempo, realçar alvos de interesse na imagem é o modelo linear de mistura espectral (MLME). O MLME estima as proporções dos diferentes tipos de materiais (denominados de componentes) em cada pixel da imagem com base em amostras de espectros puros que podem ser obtidas na própria imagem ou por meio de bibliotecas espectrais. Considerando que as respostas espectrais dos componentes analisados são conhecidas, é possível a partir de um conjunto de imagens multiespectrais ou hiperespectrais estimar as proporções de mistura no pixel. Vários trabalhos publicados na literatura especializada têm mostrado o potencial das imagens frações geradas pelo MLME para realçar: classes de uso da terra e cobertura vegetal (ADAMS et al. 1995; ROBERT et al. 1993; CARREIRAS et al. 2002; KAWAKUBO et al. 2009; KAWAKUBO et al. 2013); diferenciar áreas de floresta de capoeira (SHIMABUKURO et al. 1997); realçar florestas degradadas pela exploração da madeira (SOUZA JR. et al. 2003); e identificar queimadas (COCHRANE, SOUZA JR. 1998; SHIMABUKURO et al. 2009).

O objetivo das técnicas de classificação consiste em associar os pixels ou grupos de pixels presentes na imagem a uma determinada classe de uso da terra ou cobertura vegetal. Os classificadores tradicionais de base pixel a pixel são limitados porque se baseiam apenas no atributo espectral, deixando de lado informações importantes como o contexto. A técnica de segmentação tem sido bastante explorada na Amazônia Brasileira como uma etapa importante que antecede a classificação. A segmentação consiste em particionar a imagem em regiões homogêneas de maneira similar a fotointerpretação. Estas regiões, dependendo do aplicativo utilizado, podem guardar uma ampla 
gama de informações (valores espectrais, texturais, de tamanho, forma etc) que podem ser utilizados com sucesso na etapa de classificação. Alves et al. (1996) foram os primeiros a mapear o uso da terra na Amazônia brasileira aplicando a técnica de classificação de imagens orientada a regiões.

Com o objetivo de contribuir com os estudos regionais da Amazônia Brasileira dentro da temática de mapeamento do desmatamento utilizando sensoriamento remoto, este trabalho apresenta uma metodologia simples de classificação de imagens multitemporais utilizando modelo de mistura espectral e segmentação e classificação por regiões.

\section{ÁREA DE ESTUDO}

A área selecionada corresponde a um trecho do município de São Félix do Xingu, localizado no Sul do Estado do Pará (figura 1). A ocupação no Sul do Pará teve início na primeira metade do século XX. Migrantes vindos de diferentes partes do país passaram a se instalar na região para se dedicar à extração da borracha. No final da década de 1970 e início de 1980 a região de São Félix do Xingu passou por um novo ciclo econômico marcado pela exploração mineral e extração de madeira. Atraídos pela grande quantidade de jazidas minerais (cassiterita, ferro, ouro etc) e de madeira com alto valor no mercado (mogno), companhias de mineração e madeireiras passam a se estruturar criando um novo cenário. Esta fase abriu o caminho para o desenvolvimento da pecuária na região.

A semelhança do que aconteceu com fronteiras mais antigas, a extração de madeira e a pecuária extensiva de corte constituem atualmente a base da economia regional. O padrão de ocupação das terras é caracterizado pela predominância de fazendas com 2500 a 3000 hectares (ESCADA et al. 2005). A grande maioria das terras não é titulada e a forma do acúmulo de terras é oriunda da compra de lotes e da grilagem (termo utilizado para a falsificação de documentos com a finalidade de se apoderar de terras públicas).

Em São Félix do Xingu a pecuária não é exclusividade dos grandes latifúndios, sendo praticada nas médias e pequenas propriedades. Existem várias razões que levam os colonos e fazendeiros a optar pela pecuária. Além de ser de baixo custo e de pouca demanda de mão de obra, ela é considera um investimento de pouco risco. Muitos dos pecuaristas são originários de Goiás, Tocantins e Sul do Maranhão, que são regiões com grande tradição nesta atividade.

São Félix do Xingu convive na atualidade com sérios problemas relacionados ao desmatamento ilegal e a questão fundiária. O desmatamento na região é relativamente recente (década de 1990) representando atualmente, segundo dados do PRODES-Digital, uma das maiores taxas de desmatamento da Amazônia Brasileira (até 2008 o município já tinha desmatado 18,86\% do território, o que corresponde uma área acumulada de $15887 \mathrm{Km} 2$ ). Na tentativa de conter o avanço do desmatamento na região, o governo federal tem criado barreiras físicas com a criação de Terras Indígenas (TIs) e Unidades de Conservação. Devido à intensa grilagem e a impunidade que assola a região, São Félix do Xingu desponta no topo da lista como um dos municípios com maiores números de assassinatos ligados a conflitos de terra do território nacional.

Em termos gerais, o relevo apresenta altitudes abaixo de 300 metros nas proximidades dos principais cursos de água e altitudes mais expressivas na Serra dos Carajás (ao norte) e nos maciços dissecados localizados ao Sul, podendo chegar até 800 metros. Segundo a classificação de Koppen, o clima da região é do tipo Aw. A pluviometria anual está em torno de $1800 \mathrm{~mm}$ com concentração de chuva em 5 a 7 meses entre novembro e maio e uma seca, de 5 a 7 meses. O principal rio que corta a região é o rio Xingu, um dos principais afluentes do rio Amazonas. 


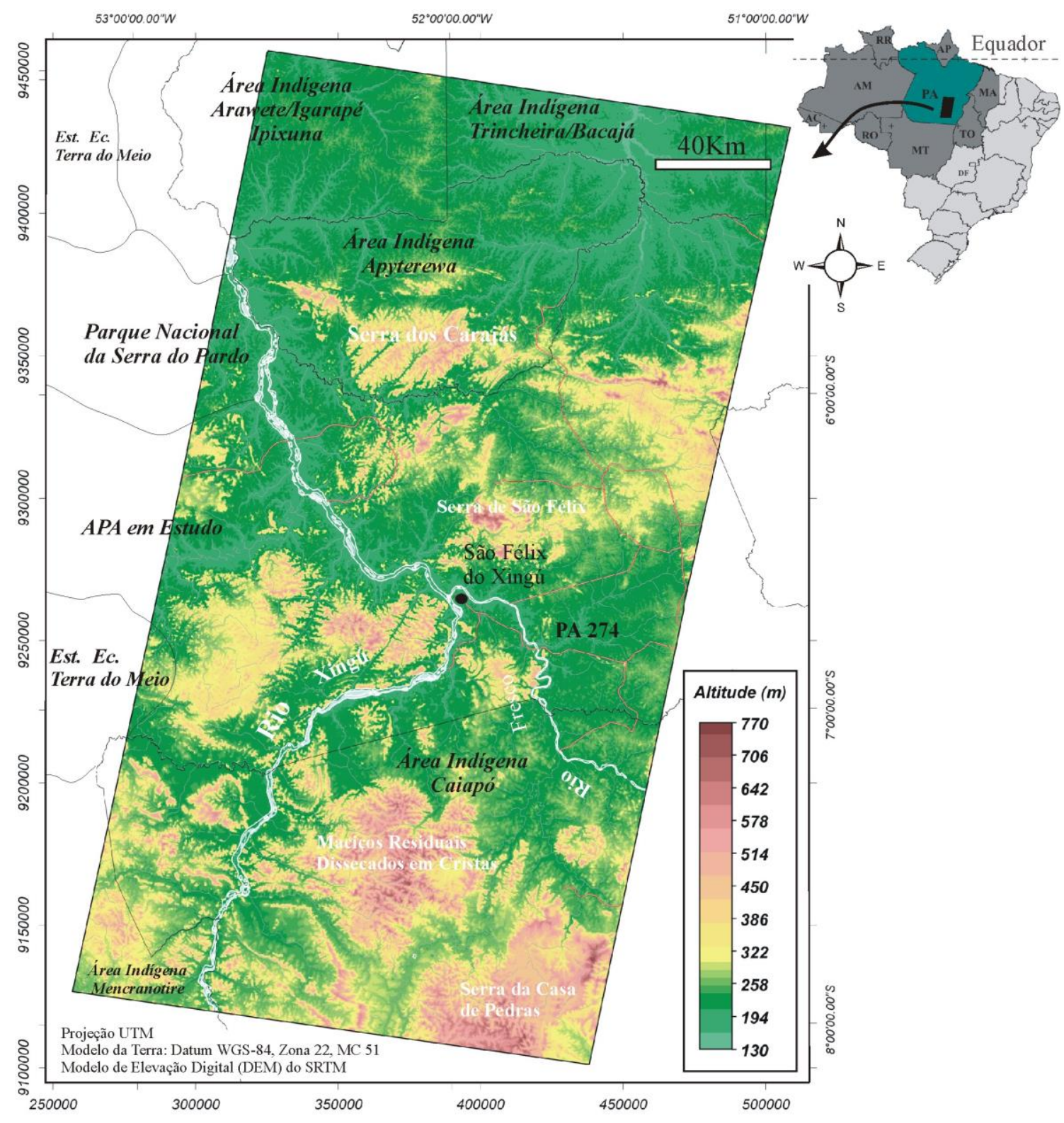

Figura 1 - Localização da área de estudo.

A região localiza-se em uma zona de transição entre os ecossistemas do cerrado e da floresta Amazônica. Conforme o mapa fitoecológico do Projeto Radambrasil, a área é dominada pela Região de Floresta Aberta. Manchas de Cerrado (Savana) são observadas a sudeste - localizadas principalmente sobre a Serra da Casa das Pedras. Faixas de contato ou zonas de transição são verificadas ao sul e oeste.

\section{METODOLOGIA}

\section{Imagens de Satélite}

A área de estudo é coberta pelo mosaico de duas cenas do satélite Landsat-5 TM referentes às órbita/pontos 225/64 e 225/65. Foram utilizadas as bandas 1 a 5 e 7 de 1992, 2000 e 2008. Este período foi escolhido por causa do intenso desmatamento observado na região. Todas as imagens selecionadas foram adquiridas nos meses de julho e agosto que correspondem ao período seco na região. Por se tratar de imagens adquiridas em datas próximas, as variações relacionadas ao ângulo de 
elevação solar, azimute e estágios fenológicos da vegetação foram minimizadas (SINGH, 1989). Conforme pode ser observado no quadro 1, todas as imagens foram adquiridas em condições de iluminação similares e com altos ângulos de elevação solar (acima de 44 graus), o que contribuiu para diminuir o efeito de sombreamento.

\section{Correção Geométrica}

Para a correção geométrica das imagens, adotou-se como referência uma composição colorida 543 em RGB do Landsat-7 ETM+ ortorretificada disponível gratuitamente no site do Global Land Cover da Universidade de Maryland, USA (www.landcover.org). Cerca de 40 pontos de controle foram identificados para cada cena, com erro médio quadrático (Root Mean Square Error) inferior a 1 pixel. Após o georreferenciemento, as imagens foram reamostradas com o interpolador vizinho mais próximo. Este interpolador foi selecionado por não alterar o valor do brilho da imagem original no processo de realocação do pixel para um novo sistema de coordenadas.

Quadro 1 - Dados das imagens Landsat-5 TM selecionadas.

\begin{tabular}{|c|c|c|c|c|}
\hline Data da & Órbita/Ponto & Horário Central (GMT) & Azimute Solar & Elevação Solar \\
\hline \multirow{2}{*}{$31 / 07 / 1992$} & $225 / 64$ & $12 \mathrm{~h} 59 \mathrm{~min}$ & 56.6016 & 45.3348 \\
& $225 / 65$ & $12 \mathrm{~h} 59 \mathrm{~min}$ & 55.5472 & 44.3555 \\
\hline $05 / 07 / 2000$ & $225 / 64$ & $13 \mathrm{~h} 13 \mathrm{~min}$ & 48.2867 & 46.0252 \\
& $225 / 65$ & $13 \mathrm{~h} 13 \mathrm{~min}$ & 47.3642 & 44.8992 \\
\hline \multirow{2}{*}{$12 / 08 / 2008$} & $225 / 64$ & $13 \mathrm{~h} 22 \mathrm{~min}$ & 56.4739 & 52.1624 \\
& $225 / 65$ & $13 \mathrm{~h} 23 \mathrm{~min}$ & 55.1314 & 51.1786 \\
\hline
\end{tabular}

Bandas selecionadas (em unidade de $\mu \mathrm{m}$ ):

Banda $1=0,45-0,52(0,48)$; Banda $2=0,52-0,60(0,56)$; Banda $3=0,63-0,69(0,66)$; Banda $4=0,76-0,90(0,83)$;

Banda $5=1,55-1,75(1,65)$; Banda $7=2,08-2,35(2,2)$.

Resolução nominal das bandas multiespectrais: 30 metros.

Faixa abrangida por cada cena (swath): $180 \mathrm{~km}$

\section{Calibração Radiométrica e Modelo de Mistura}

O conjunto de imagens TM de 2008 (órbita/ponto 225/64) foi utilizado como referência para a calibração. O efeito atmosférico foi corrigido por meio do método de subtração do pixel de escuro de Chavez (1988). Em seguida, os valores expressos em números digitais (DNs) foram convertidos para valores físicos de radiância (expressos em W/(m2.sr. $\mu \mathrm{m})$ e no passo seguinte, para refletância segundo os procedimentos descritos por Chander e Markham (2003). Optou-se por não utilizar os coeficientes de pré ou de pós calibração para as outras datas (além das imagens de 2008) porque não foi feito nenhum controle de campo para verificar a sua acurácia (ADAMS et al. 1995).

Todas as imagens brutas (expressas em DNs) foram padronizadas radiometricamente em relação a imagem-referência (já calibrada para reflectância) por meio da técnica do empirical line. A técnica do empirical line fornece um meio relativamente simples de calibração e conversão dos números digitais (DNs) da imagem para valores físicos de reflectância. Tradicionalmente a técnica combina os DNs de alvos selecionados na imagem (alvos claros e escuros) com os seus respectivos dados de reflectância medidos em campo ou em laboratório (SMITH; MILTON, 1999). Os DNs são transformados para valores de reflectância adotando a equação:

$$
\text { Refl }_{k}=\text { ganho }_{k} \times \text { DN }_{k}+\text { offset }_{k}
$$


Onde:

Reflk = valor de reflectância na banda k; ganhok = termo multiplicativo;

$\mathrm{DNk}=$ número digital (0-255);

offsetk $=$ termo aditivo.

A seleção dos espectros puros (image endmembers) utilizados para a calibração no empirical line foi feita de maneira interativa e integrada com a análise de mistura espectral. O mesmo conjunto de endmembers que forneceu o melhor resultado no modelo de mistura espectral (aquele que gerou imagens-frações com proporções de misturas condizentes com a estrutura da paisagem e com menor erro na imagem-resíduo - RMS) foi selecionado para a calibração. A estimativa de mistura dentro de cada pixel da imagem foi feita adotando o modelo linear de mistura espectral (MLME). A equação do modelo é escrita da seguinte maneira:

$$
R_{i}=\sum_{i=1}^{n} R_{i k} F_{k}+E_{i}
$$

A seguinte restrição é definida:

$$
\sum_{i=1}^{n} F_{k}=1
$$

$$
\begin{aligned}
& \text { A imagem-resíduo é calculada por: } \\
& \operatorname{RMS}=\left[1 / \mathrm{n} \sum \mathrm{E}_{\mathrm{i}}{ }^{2}\right]^{1 / 2}
\end{aligned}
$$

O efeito da não-linearidade de mistura causada pelo múltiplo espalhamento da radiação foi considerado neste trabalho como sendo secundário (ADAMS et al. 1995) em relação à dominância linear que rege a interação dos elementos presentes na paisagem. O múltiplo espalhamento ocorre principalmente na faixa do infravermelho próximo (correspondendo a banda 4 do TM) e encontra-se bem descrito no trabalho de Robert et al. (1993).

\section{Segmentação e Classificação}

Foram geradas composições coloridas multitemporais (CCMT) utilizando as frações-sombra geradas pelo modelo linear de mistura espectral (MLME). As mudanças observadas ao longo das datas utilizando a CCMT são interpretadas da seguinte forma (MORATO et al. 2011): as mudanças são representadas por cores e as áreas de "não-mudanças", em tonalidades de cinza (feições altamente correlacionadas e que se posicionam ao longo do eixo acromático).

A fração sombra foi utilizada porque é bem correlacionada com a estrutura do dossel florestal: áreas de floresta tropical intacta, em função da rugosidade do dossel, possuem média quantidade de sombra enquanto as áreas desmatadas possuem baixa quantidade (SHIMABUKURO et al. 1997). 
Áreas de regeneração cobertas por capoeira, frequentemente são confundidas com florestas. Na fração sombra, as capoeiras são identificadas por apresentar baixa quantidade de sombra (porque possui dossel homogêneo) e elevada proporção de vegetação.

Com o objetivo de facilitar a interpretação e permitir a realização de uma análise quantitativa do desmatamento, a CCMT foi submetida à classificação. Inicialmente, as imagens foram suavizadas com um filtro de mediana com a finalidade de reduzir a variabilidade interna das classes e preservar ao mesmo tempo as informações de borda que é importante para a segmentação (KAWAKUBO et al. 2009). Em seguida, a CCMT foi submetida a segmentação por crescimento de regiões utilizando o Sistema de Informação Geográfica SPRING 5.0.4 desenvolvido pelo INPE (CÂMARA et al. 1996).

O método de segmentação por crescimento de regiões foi escolhido por causa das vantagens que ele oferece: ser amplamente utilizados em aplicações de sensoriamento remoto; criar regiões homogêneas e fechadas; ser representativo das atuais gerações de técnicas de segmentação (TILTON, LAWRENCE, 2000; ESPINDOLA et al. 2006). Dois parâmetros são definidos pelo usuário na segmentação por crescimento de regiões: os valores de Similaridade e de Área (BINS et al. 1996). $\mathrm{O}$ valor de Similaridade corresponde à distância euclidiana média dos valores espectrais de cada região. O valor de Área corresponde à área mínima em número de pixels a serem individualizadas na segmentação.

A classificação das regiões segmentadas foi realizada com um algoritmo do tipo clustering por regiões batizado de ISOSEG, que calcula o centro de cada classe utilizando a matriz de covariância e o vetor-média das regiões (BINS et al. 1992). Para a sua aplicação, inicialmente seleciona-se uma imagem ou um conjunto de imagens para a construção do espaço de atributos (no caso especifico imagens multitemporais que representam o conteúdo de sombra no pixel). Em seguida, define-se um limiar de aceitação (expresso em porcentagem) que corresponde à distância máxima de Mahalanobis. Os clusters gerados pelo ISOSEG são posteriormente identificados visualmente, na tela do computador, associando manualmente cada cluster a uma legenda pré-definida. Esta associação foi feita com o auxílio da composição colorida Landsat-5 TM 5R4G3B. O resultado da classificação foi comparado com os dados de desmatamento do PRODES-Digital.

\section{RESULTADOS}

Foram realizados vários testes para a escolha do conjunto dos endmembers a ser utilizado tanto no procedimento de calibração quanto na modelagem de mistura espectral. A figura 2 ilustra um gráfico contendo 5 espectros coletados diretamente da imagem (image endmembers): vegetação (Veg.) Sombra, Solo Exposto (chamado apenas de Solo), Estrada e Vegetação Não-Fotossintética (NPV, do inglês, Non-Fotossintetic Vegetation). O conjunto que forneceu o melhor ajuste na estimativa de mistura foi composto pelos endmember de Solo Exposto, Sombra e Vegetação. Na calibração pelo método empirical line, o ajuste R2 foi superior a 0,91 para todas as imagens selecionadas.

Durante a fase de adequação dos endmembers, um resultado interessante foi adquirido quando quatro endmembers foram incluídos no modelo (Vegetação, Solo, Sombra e NPV). A imagem-fração NPV revelou-se excelente para mapear diferentes classes de queimada. A imagem NPV amplificou o sinal das queimadas em função da quantidade de materiais secos dispostos na superfície. Por outro lado, a inclusão da fração NPV aumentou significativamente os erros da modelagem. Quando considerado apenas as componentes Vegetação, Solo e Sombra, os erros da modelagem foram reduzidos. O valor médio do erro expresso pela imagem-resíduo RMSE (root mean square error) foi de 0,0047 , o que representa quantitativamente uma boa adequação do conjunto de referência (WU et al. 2005). 


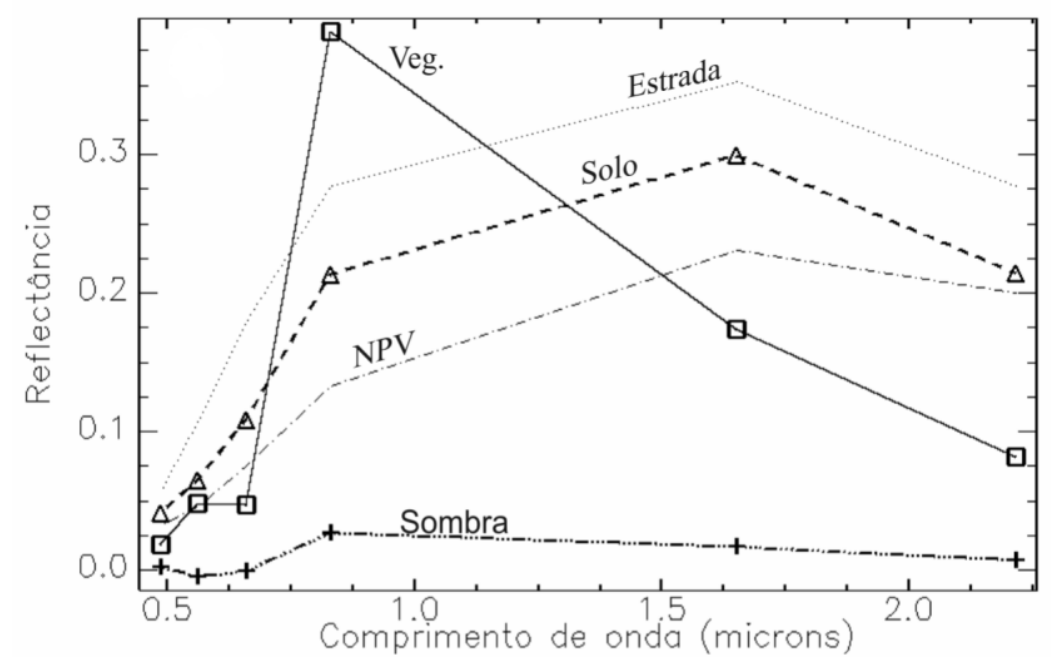

Figura 2 - Espectros puros obtidos na imagem (image endmembers). Os endmembers de Vegetação (Veg.) e Vegetação Não-Fotossintética (NPV) foram obtidos em uma área de capoeira e de pastagem seca, respectivamente.

A figura 3 ilustra o mosaico das imagens-frações de 2008: solo, sombra, vegetação e a imagem-erro (RMSE image). Conforme pode ser observado, as áreas de floresta, não-floresta e os corpos d'água são bem destacados nas imagens-frações. Valores negativos próximos de zero foram verificados principalmente na imagem-fração solo nas áreas cobertas por floresta. Os valores negativos e maiores do que 1 (extrapolação) foram substituídos por 0 e 1, respectivamente.

$\mathrm{Na}$ fração solo as áreas cobertas por florestas aparecem em preto, indicando pouca ou nenhuma interação da radiação com o solo. As áreas desmatadas (que incluem dominantemente as classes de campo/pastagem e solo exposto) possuem proporções bem maiores de solo em sua mistura, aparecendo com tonalidades que variam do cinza ao branco. A fração sombra realçou os corpos de água e as queimadas recentes. As áreas de floresta, por causa da rugosidade do dossel, apresentaram média proporção de sombra (cinza), diferenciando-se das áreas desflorestadas com baixa quantidade de sombra em sua estrutura (cinza escuro e preto). As áreas de capoeira também apresentam baixa proporção de sombra, permitindo a sua separação com as áreas de floresta. As áreas cobertas por vegetação aparecem com tonalidades claras na imagem-fração vegetação (floresta e capoeira), contrastando-se com as áreas com ausência de cobertura vegetal e os corpos de água, que aparecem em preto. A imagem RMS mostra que as áreas com presença de fumaça e brumas apresentaram maiores erros na modelagem em função da pouca adequação com os componentes empregados. $\mathrm{O}$ rio Xingu também apresentou elevados erros em razão dos sedimentos carreados não se adequarem ao espectro de sombra. A técnica do modelo de mistura espectral tem se mostrado eficiente para isolar ruídos e brumas existentes na imagem por meio da imagem-resíduo. 

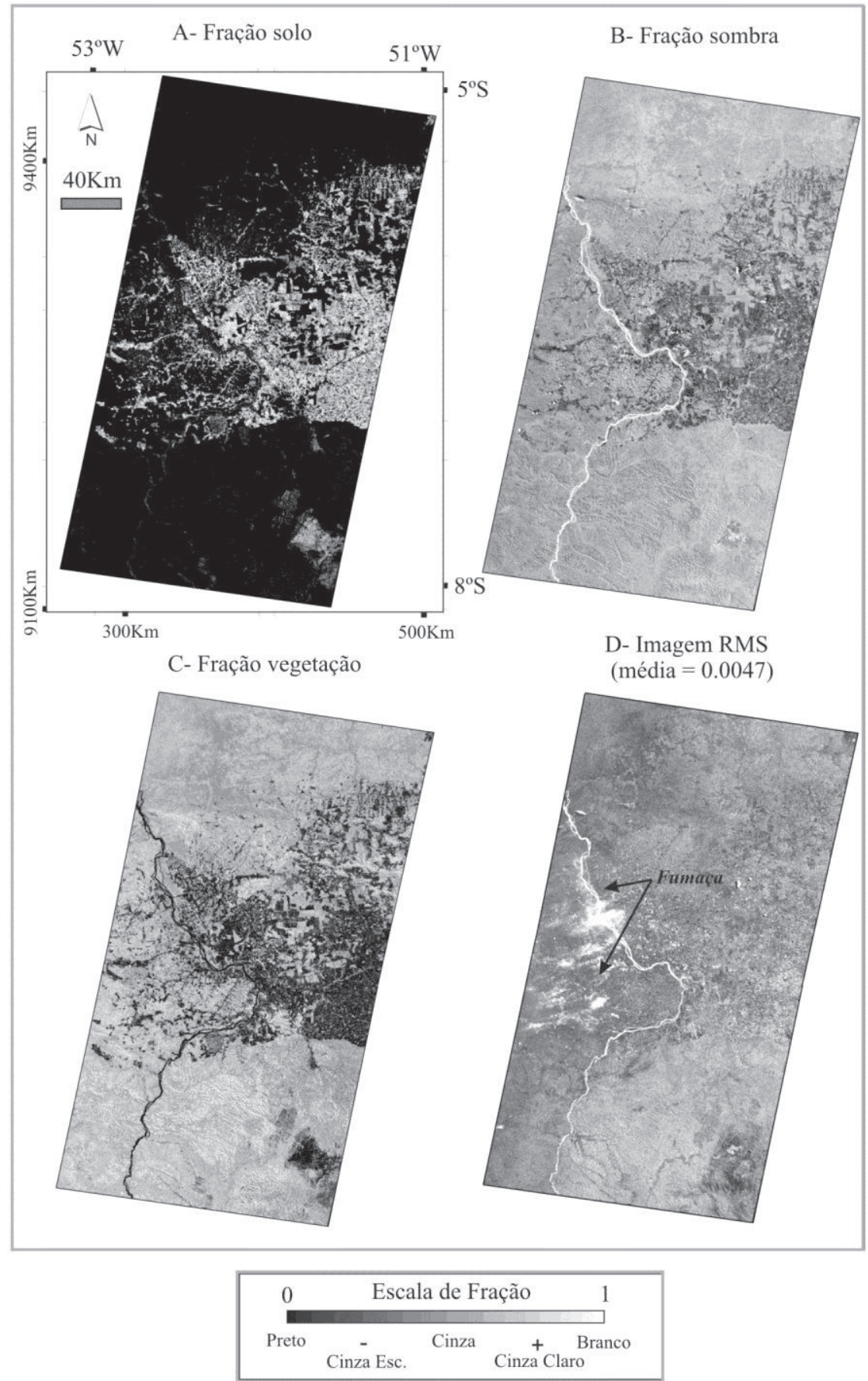

Figura 3 - Imagens-frações derivada do modelo linear de mistura espectral (MLME). As proporções de mistura foram estimadas das bandas 1 a 5 e 7 do satélite Landsat-5 TM de 2008, órbita/ponto 225/64-65.

A figura 4 ilustra a composição colorida multitemporal (CCMT) utilizando a fração sombra. Uma inversão dos valores foi aplicada às imagens para que as áreas com maior proporção de sombra fossem exibidas em tonalidades escuras e as áreas com baixa proporção em tonalidades claras, facilitando assim a interpretação. Conforme pode ser observado, a CCMT revela nitidamente as áreas desmatadas ao longo dos anos. As áreas em branco representam os desmatamentos mais antigos (verificados desde 1992). As áreas em verde e amarelo correspondem os desmatamentos ocorridos em 2000. A cor vermelha ilustra os desmatamentos mais recentes registrados na imagem de 2008. 


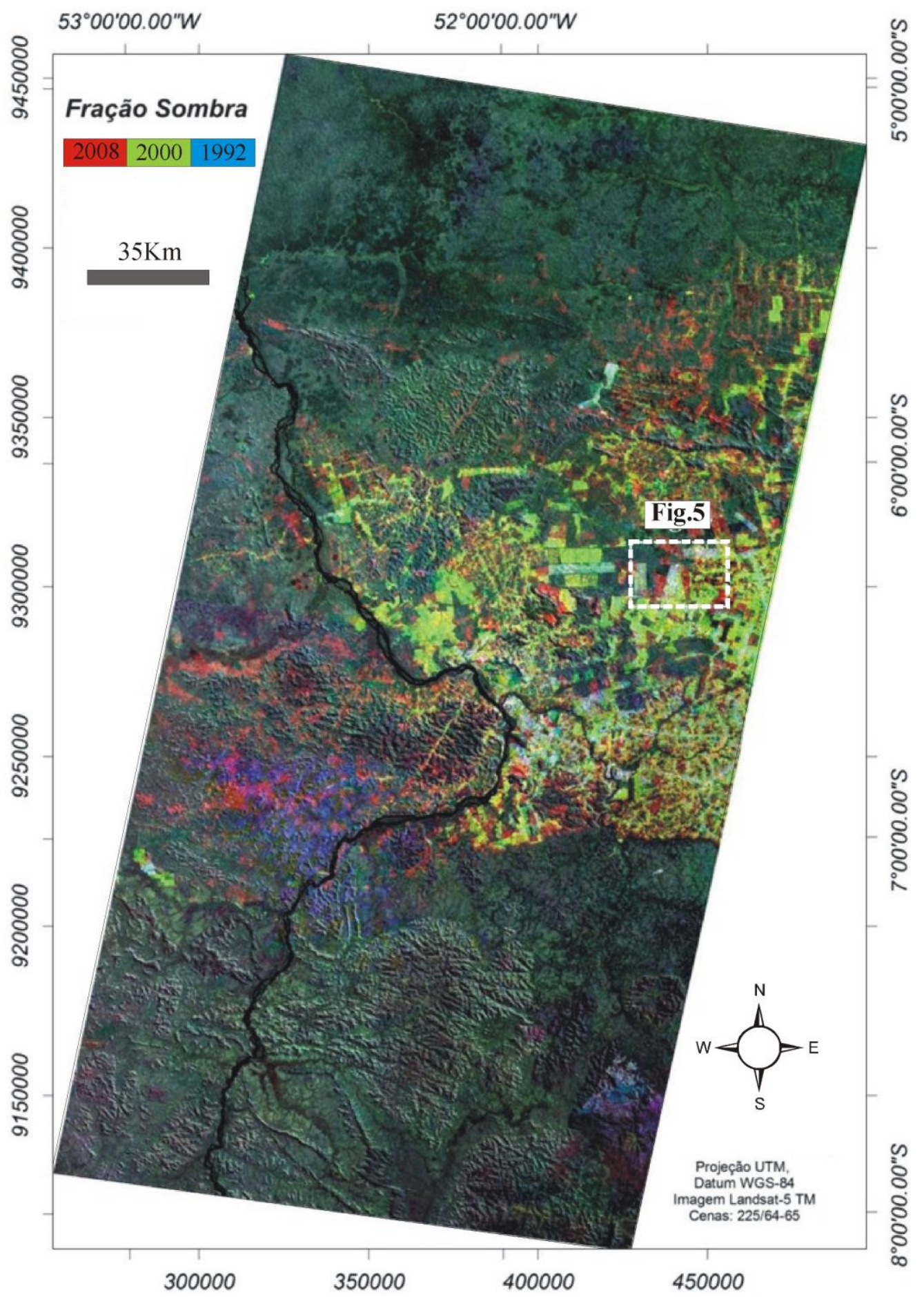

Figura 4 - Composição colorida multitemporal utilizando a fração sombra. As áreas com maiores proporções de sombra apresentam valores mais baixos em função da inversão dos valores no modelo de mistura.

Foram utilizados para a segmentação da CCMT os seguintes limiares: 25 para similaridade e 30 para área mínima. Para o agrupamento das regiões segmentadas, adotou-se na rotina ISOSEG o limiar de 99,9\%. Os clusters gerados pelo ISOSEG foram agrupados em 5 classes: Água, Floresta, Desmatamento (1992); Desmatamento (2000) e Desmatamento (2008). A figura 5 ilustra as etapas mencionadas: (a) segmentação com o algoritmo por crescimento de regiões; (b) aplicação do classificador não-supervisionado por regiões ISOSEG; (c) reagrupamento dos clusters gerados com base numa legenda previamente definida. 


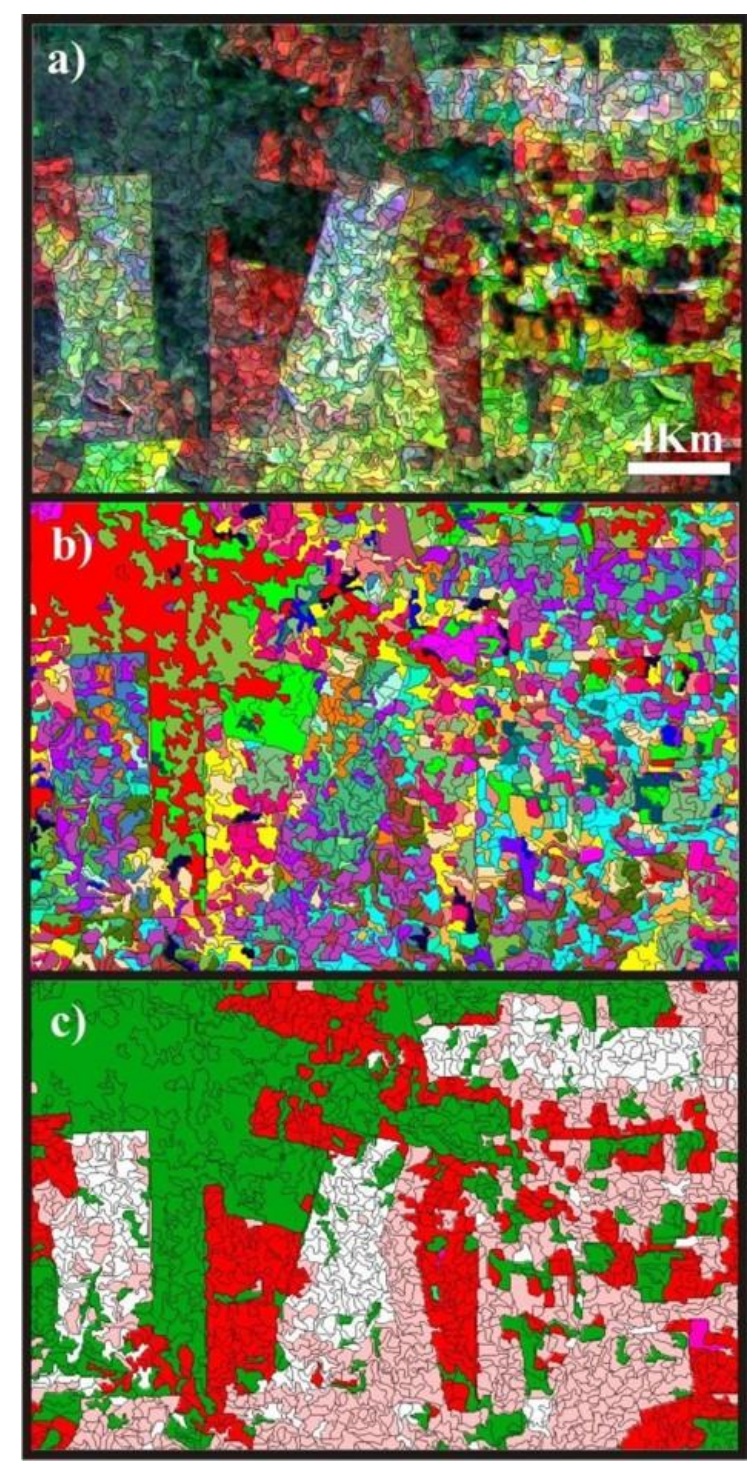

Figura 5 - Segmentação e agrupamento das regiões com o classificador não-supervisionado ISOSEG. (a) A imagem de fundo representa a composição colorida multitemporal utilizando a fração sombra R 2008, G 2000 e B 1992 . As áreas em branco representam os desmatamentos mais antigos (verificados desde 1992). As áreas em verde e amarelo

correspondem os desmatamentos ocorridos em 2000. A cor vermelha ilustra os desmatamentos mais recentes registrados na imagem de 2008. A segmentação foi feita utilizando os limiares 25 (similaridade) e 30 (área mínima);

(b) agrupamento das regiões segmentadas com o algoritmo ISOSEG; (c) reagrupamento e rotulação dos clusters.

Os resultados da classificação são mostrados na figura 6. Para o ano de 1992 foi calculado $1.082 \mathrm{Km}^{2}$ de área desmatada. No ano de 2000, o desmatamento aumentou 4 vezes, atingindo o valor de $4.358 \mathrm{Km}^{2}$. No ano de 2008 , o incremento do desmatamento foi um pouco abaixo do registrado em $2000 \mathrm{com} 4.000 \mathrm{~km}^{2}$. O desmatamento acumulado correspondeu a $9.440 \mathrm{Km}^{2}$. As áreas ocupadas por florestas, cerrados e água correspondem a $48.320 \mathrm{Km}^{2}$, totalizando uma área mapeada de $57.765 \mathrm{Km}^{2}$.

Os valores de desmatamento acumulado apresentados neste trabalho são inferiores ao do PRODES-Digital, que apresenta até o ano de 2008 um desmatamento acumulado de $12.428 \mathrm{Km} 2$. Esta diferença se deve provavelmente a generalização da segmentação. A utilização de limiares mais baixos aumentaria o particionamento da imagem e consequentemente o detalhe da classificação.

Analisando a expansão do desmatamento observa-se que em 1992 os focos de desmatamento se concentravam basicamente ao longo das estradas vicinais e principalmente nas proximidades da rodovia PA-279 que liga São Félix do Xingu a região leste do Estado. Em 2000 houve uma rápida 
expansão do desmatamento ao longo da margem direita do rio Xingu e na porção nordeste da área de estudo. Em 2008 a área desmatada continuou crescendo em ritmo frenético. O desmatamento se intensificou nas áreas observadas em 2000 e uma nova frente de desmatamento começou a ser estruturada ao longo da margem esquerda do rio Xingu (região chamada de Terra do Meio).



Figura 6 - Mapa da dinâmica do desmatamento da região de São Félix do Xingu, Sul do Pará.

O avanço do desmatamento para dentro da Terra do Meio tem trazido sérias preocupações por parte de ambientalistas e órgãos governamentais. Caso esta nova frente se consolide, ela pode vir 
a se conectar com a frente de ocupação originária da Rodovia Cuiabá-Santarém que corta o Estado no sentido Sul-Norte formando uma gigantesca área de destruição do ecossistema natural. Por este motivo, o governo federal tem criado "barreiras" para conter este avanço: ao norte encontra-se as Terras indígenas (TIs) Arawete/Igarapé Ipixuna, Trincheira/Bacajá e Apyterewa; ao sul estão localizadas as TIs Caiapó e Mencranotire; a leste, atravessando o rio Xingu encontram-se a Estação Ecológica Terra do Meio e o Parque Nacional Serra do Pardo (ambos criado por decreto presidencial de 2005, somando uma área superior a 3,7 milhões de hectares).

Muitos ambientalistas acreditam que as medidas tomadas pelo governo federal têm surgido efeitos positivos. A criação da Estação Ecológica Terra do Meio e do Parque Nacional Serra do Pardo fez reduzir o preço das terras no movimentado mercado local de grilagem. Apesar disto, a extração ilegal de madeiras e as ocorrências de queimadas ainda continuam dentro das Unidades de Conservação. Fontes não oficiais têm revelado informações alarmantes. Para evitar a fiscalização, madeireiras ilegais e fazendeiros estariam trabalhando durante a noite e até em época de chuva (quando o corte das árvores é usualmente suspenso) como forma de "driblar" a fiscalização. Estariam também, multiplicando os desmatamentos menores que 25 hectares como o objetivo de dificultar a identificação pelo sistema Deter do INPE. Para que o governo federal faça cumprir as restrições impostas, é necessária uma fiscalização ostensiva na região e aplicação de punições severas para aqueles que tentam burlar a lei.

\section{CONSIDERAÇÕES FINAIS}

As áreas desmatadas foram realçadas por meio de cores utilizando a fração sombra derivada do modelo de mistura espectral. A imagem fração sombra é bem correlacionada com a estrutura do dossel florestal: áreas cobertas por florestas primárias possuem média proporção de sombra em suas estruturas enquanto áreas as desmatadas (solo exposto, pastagem e áreas de rebrota) possuem baixos valores. Esta diferença permite a separação das áreas cobertas por florestas das áreas que sofreram processo de desmatamento. A metodologia adotada mostrou-se eficiente para o monitoramento do desmatamento, podendo ser empregada na estruturação de um banco de dados geográfico com o objetivo de apoiar fiscalização do desmatamento na região. Comparando os resultados das classificações foi possível traçar algumas tendências no processo de desmatamento e ocupação da região. O desmatamento se intensificou principalmente a partir de 2000. Com o mapa de 2008 foi possível observar novas frentes de desmatamento que se dirigindo para Nordeste, Noroeste (paralelas ao rio Xingu) e Oeste (adentrando-se para a Terra do Meio). O aumento do número de cabeças de boi acompanhou o ritmo frenético do desmatamento, o que leva a crer que a atividade pecuária seja a principal indutora do desmatamento na região. O governo federal tem tomado algumas medidas importantes com o objetivo de conter o avanço descontrolado do desmatamento na região. A criação de Terras Indígenas e Unidades de Conservação têm exercido um importante papel no sentido de dificultar o desmatamento em certas localidades, porém não impede a ocorrência de desmatamento mesmo dentro dos seus limites. Para que a lei seja cumprida, é preciso uma política ostensiva de fiscalização na região e punições enérgicas contra aqueles que atentam contra o patrimônio público e que usam da violência para garantir as suas reivindicações.

\section{AGRADECIMENTOS}

Os autores agradecem as valiosas contribuições prestadas por Frank Nabeta que revisou com competência e prontidão o presente manuscrito. Agradecimento também a CAPES pelo apoio financeiro prestado para a execução deste trabalho. 


\section{BIBLIOGRAFIA}

ADAMS, J. B.; SABOL, D. E.; KAPOS, V.; AILMEIDA FILHO, R.; ROBERTS, D. A.; SMITH, M. O.; GILLESPIE, A. R. Classification of multispectral images based on fractions of endmembers: application to land-cover change in the Brazilian Amazon. Remote Sensing of Environment, New York, v. 52, p. 137$154,1995$.

ALVES, D. S.; MOREIRA, J. C.; KALIL, E. M.; SOARES, J. V.; FERNANDEZ, O.; ALMEIDA, S.; ORTIZ, J. D.; AMARAL, S. Mapeamento do uso da terra em Rondônia utilizando técnicas de segmentação e classificação de imagens TM. In: SIMPÓSIO BRASILEIRO DE SENSORIAMENTO REMOTO, 1996, Salvador. Anais... São José dos Campos: INPE, 1996.

BINS, S. A.; ERTHAL, G. J.; FONSECA, L. M. G. Um método de classificação não supervisionado por regiões. In: SIMPÓSIO BRASILEIRO DE COMPUTAÇÃO GRÁFICA E PROCESSAMENTO DE IMAGENS, 1992, Águas de Lindóia. Anais... Águas de Lindóia: SBC, 1992.

BINS, S. A.; FONSECA, L. M. G.; ERTHAL, G. J.; LI, F. M. Satellite imagery segmentation: a region growing approach. In: SIMPÓSIO BRASILEIRO DE SENSORIAMENTO REMOTO, 1996, Salvador. Anais... São José dos Campos: INPE, 1996.

CÂMARA, G.; SOUZA, R. C. M.; FREITAS, U. M.; GARRIDO. J.; LI, M. F. SPRING: integrating remote sensing and GIS with object-oriented data modeling. Computers and Graphics, Amsterdam, v. 15, p. 1322, 1996.

CARREIRAS, J. M. B.; SHIMABUKURO, Y. E.; PEREIRA, J. M. C. Fraction images derived from SPOT-4 Vegetation data to assess land-cover change over the State of Mato Grosso, Brazil. International Journal of Remote Sensing, London, v. 23, n. 23, p. 4979-4983, 2002.

CHANDER, G.; MARKHAM, B. Revised Landsat-5 TM radiometric calibration procedures and postcalibration dynamic ranges. IEEE Transaction on Geoscience and Remote Sensing, New Jersey, v. 41, n. 11, p. 2674-2677, 2003.

CHAVEZ, P. S. An improved dark-object subtraction techique for atmospheric cattering correction of multispectral data. Remote Sensing of Environment, New York, v.24, n.3, p. 459- 479, 1988.

COCHRANE, M. A.; SOUZA JR., C. Linear mixture model classification of burned forest in the eastern Amazon. International Journal of Remote Sensing, London, v. 19, n. 17, p. 3433-3440, 1998.

ESCADA, M.I.S. VIEIRA, I.C.G., KAMPEL, S.A., ARAÚJO, R., VEIGA, J.B. Occupation processes in the new Amazonian frontiers: the Xingu/Iriri region. Estudos Avançado, v.19, n. 54, p. 9-23, 2005.

ESPINDOLA, G. M.; CAMARA, G.; REIS, I. A.; BINS, L. S.; MONTEIRO, A. M. Parameter selection for region-growing image segmentation algorithms using spatial autocorrelation. International Journal of Remote Sensing, London v. 27, n. 14, p. 3035-3040, 2006.

INPE Monitoramento da cobertura florestal da Amazônia por satellites: sistemas PRODES, DETER, DEGRAD e QUEIMADAS, 2007-2008. São José dos campos: INPE, 2008.

KAWAKUBO, F. S; MORATO, R. G.; MIDAGLIA, C. L; GOMIDE, M. L. C.; LUCHIARI, A. Land-use and vegetation-cover mapping of an indigenous land area in the state of Mato Grosso (Brazil) based on spectral linear mixing model, segmentation and region classification. Geocarto International, v. 24, n. 2, p. 165-175, 2009.

KAWAKUBO, F. S; MORATO, R. G.; LUCHIARI, A. Use of fraction imagery, segmentation and masking techniques to classify land-use and land-cover types in the Brazilian Amazon. International Journal of Remote Sensing, v. 34, n. 15, p. 5452-5467, 2013.

LUCAS, R. M.; HONZAK, M.; CURRAN, P. J.; FOODY, G. M.; MILNE, R.; BROWN, T.; AMARAL, $\mathrm{S}$. Mapping the regional extent of tropical forest regeneration stages in the Brazilian Legal Amazon using NOAA AVHRR data. International Journal of Remote Sensing, London, v. 21, p. 2855-2881, 2000.

LUCAS, R. M.; XIAO, X.; HAGEN, S.; FROLKING, S. Evaluating TERRA-1 MODIS data for discriminating of tropical secondary forest regeneration stages in the Brazilian Legal Amazon. Geophysical Research Letters, Florida, v. 29, n. 8, 2002, p. 42/1-42/4.

MARGULIS, S. Causas do desmatamento da Amazônia brasileira. Brasília: Banco Mundial, 2003. 
MORATO, R. G.; KAWAKUBO, F. S.; HAYAKAWA, E. R.; MACHADO, R. P. P. Análise da expansão urbana por meio de composições coloridas multitemporais. Mercator, v. 10, n. 22, p. 221-213, 2011.

MORTON, D. C.; DEFRIES, R. S.; SHIMABUKURO, Y. E.; ANDERSON, L. O.; ARAI, E.; ESPIRITO-SANTO, F. D. B.; FREITAS, R.; MORISETTE, J. Cropland expansion changes deforestation dynamics in the southern Brazilian Amazon. The National Academy of Sciences of the USA, Washington, DC, v. 103, n. 39, p. 14637-14641, 2006.

OLIVEIRA, M.; VEIGA. I. Meio ambiente e as novas formas de ocupação da Amazônia: o caso da fronteira de São Félix do Xingu. In: CONGRESSO LATINOAMERICANO DE SOCIOLOGIA RURAL, 2006, Quito, Equador. Anais... Quito, 2006.

RADAMBRASIL Mapa Fitoecológico da Folha Araguaia/Tocantins SB/SC22. Rio de Janeiro: Ministério das Minas e Energia, 1974.

ROBERTS, D. A.; SMITH, M. O.; ADAMS, J. B. Green vegetation, nonphotosyntetic vegetation, and soils in AVIRIS data. Remote Sensing of Environment, New York, v. 44, p. 255-269, 1993.

RODRIGUES-YI, J. L.; SHIMABUKURO, Y. E.; RUDORFF, B. F. T. Image segmentation for classification of vegetation using NOAA AVHRR data. International Journal of Remote Sensing, London, v. 21, n. 1, p. $167-172,2000$.

SHIMABUKURO, Y. E.; BATISTA, G. T.; MELLO, E. M. K.; MOREIRA, J. C.; DARTE, V. Using shade fraction image segmentation to evaluate deforestation in Landsat Thematic Mapper images of the Amazon region. International Journal of Remote Sensing, London, v. 19, n. 3, p. 535-541, 1998.

SHIMABUKURO, Y. E.; DUARTE, V.; ARAI, E.; FREITAS, R. M.; LIMA, A.; VALERIANO, D. M.; BROWN, I. F.; MALDONADO, M. L. R. Fraction images derived from Terra Modis data for mapping burnt areas in Brazilian Amazônia. International Journal of Remote Sensing, London, v. 30, n. 6, p. 1537-1546, 2009. SINGH, A. Digital change detection techniques using remotely-sensed data. International Journal of Remote Sensing, London, v. 10, n. 6, p. 989-1003.

SMITH, G. M.; MILTON, E. J. The use of the empirical line method to calibrate remotely sensed data to reflectance. International Journal of Remote Sensing, London, v. 20, n. 13, p. 2653-2662, 1999.

SOUZA JR., C.; FIRESTONE, L.; SILVA, L. M.; ROBERTS, D. A. Mapping forest degradation in the Eastern Amazon from SPOT 4 through spectral mixture models. Remote Sensing of Environment, New York, v. 87, p. 494-506, 2003.

SOUZA JR., C.; ROBERTS, D. A. Mapping forest degradation in the Amazon region with Ikonos images. International Journal of Remote Sensing, London, v. 26, p. 425-229, 2005.

TILTON, J.; LAWRENCE, W. Interactive analysis of hierarchical image segmentation. In: INTERNATIONAL GEOSCICENCE AND REMOTE SENSING SYMPOSIUM, 2000, New York, USA. Anais... New York: IEEE, 2000.

VEIGA, J. B.; TOURRAND, J. F.; PIKETTY, M. G.; POCCARD-CHAPUIS, R.; ALVES, A. M.; THALES, M. C. Expansão e Trajetórias da Pecuária na Amazônia. Brasília: Editora da UNB, 2004.

WU, J.; XU, J.; YUE, W. V-I-S model for cities that are experiencing rapid urbanization and development. In: PROCEEDINGS OF THE IEEE INTERNATIONAL GEOSCIENCE AND REMOTE SENSING, Seoul, Korea. Anais... New York: IEEE, 2005.

Trabalho enviado em abril de 2013

Trabalho aceito em junho de 2013 